\title{
Research on Full-Time Master of Mathematics Education Candidates' Cognition of Dissertation
}

\author{
Zezhong Yang, Dandan Sun \\ The School of Mathematics, Shandong Normal University, Jinan, China \\ Email: zhongzee@163.com
}

Received 26 September 2015; accepted 11 October 2015; published 14 October 2015

Copyright $@ 2015$ by authors and Scientific Research Publishing Inc.

This work is licensed under the Creative Commons Attribution International License (CC BY). http://creativecommons.org/licenses/by/4.0/

(c) (7) Open Access

\begin{abstract}
This research focused on the cognition of full-time candidates of master of mathematics education to their dissertation, and adopted open-ended structure questionnaire. There were 94 participants from 11 normal universities in Mainland China. The questionnaires were sent to them by e-mail. The results indicated the majority of candidates thought: 1) The dissertation was a paper with rational structure $(\mathbf{7 8 . 3 8 \% )} ; 2)$ The characteristic of good master dissertation was that its view was usually original $(71.62 \%)$ and valuable and its content was rich $(64.85 \%)$; 3 ) Reading more relevant literature to understand research status $(\mathbf{9 8 . 6 5 \% )}$ ) and learning more fundamental theories (75.68\%) was necessary before writing dissertation; 4) They should refer the form of relevant dissertation usually when writing dissertation $(72.97 \%)$. So it was obvious that many candidates' cognition about dissertation and its preparing and writing was quite superficial, some of them were even false.
\end{abstract}

\section{Keywords}

Mathematics Education, Master of Education, Candidates, Cognition, Dissertation

\section{Introduction}

Due to having many serious problems, the quality of dissertation of full-time candidates of master of mathematics education was always not high these years in Mainland China [1]. This situation has got the wide and high attention of many educators, and a series of researches has been made and many results have been obtained by now, such as Yang Qiliang thought its reason was mainly the unreasonable arrangement of supervisors and lack of standard [2]. Li Gaofen and Yang Zupei argued its reason was mainly the insufficient learning and practicing 
about research methods [3]. Zhang Dingqiang claimed its main reason was the imperfect cultivation system [4]. However, by reviewing these studies, it can be easily found they all are almost based on the author's teaching experience and their reasoning, while the study which is based on the investigation to candidates does not appear yet at present. Indeed the investigation study is necessary and important to find the real reason, so we investigated the cognition of full-time master of mathematics education candidates. We believe the cognition of these candidates can profoundly and extensively influence their writing of dissertation, because modern psychological researches had revealed that people's cognition could influence their behavior directly, what kind of cognition the people had, then they would have what kind of behaviors correspondingly.

\section{Methodology}

\subsection{Instrument}

To find out the candidates' real thoughts extensively and deeply, we adopted open-ended structure questionnaire on the base of the relevant questionnaire. Our questionnaire questions are related to (a) the cognition about master degree dissertation, (b) the cognition about good master degree dissertation, (c) preparing for the master degree dissertation, (d) the writing of good master degree dissertation.

\subsection{Participants}

We chose 94 full-time candidates of master of mathematics education randomly from Dongbei normal university, Beijing normal university, Shandong normal university, Nanjing normal university, Huanan normal university, Anhui normal university, Fujian normal university, Sichuan normal university, Shanxi normal university, Huaibei normal university and Qufu normal university. They all were freshmen of postgraduates majoring in mathematics education, including 68 female candidates and 26 male candidates. The questionnaires were sent to them by e-mail. We asked them to send back in two weeks.

\subsection{Data Collection}

We recalled 87 questionnaires two weeks later and checked them according to the following two criteria: a) all questions were answered; b) all answers are consistent and complete. We obtained 74 effective questionnaires finally.

\subsection{Data Analysis}

Since our questions are open-ended, we analyzed answers with software Nvivo 10 at first, then calculated the percentages of every statements obtained by software Nvivo 10. All answers were analyzed through these percentages.

\section{Results}

\subsection{The Cognition about Master Degree Dissertation}

After analyzing with software Nvivo 10, we obtained totally 19 different statements on master degree dissertation. The statements which its holders are more than $5 \%$ are shown in Table 1.

From Table 1 we know the majority (78.38\%) of candidates thought the dissertation was a paper with rational structure, more than a half candidates thought the dissertation was a paper with rich content and enough number of words, only a little part (less 10\%) of candidates thought that the dissertation should be a paper with a analysis of a problem and some reasonable methods.

\subsection{The Cognition of Good Master Degree Dissertation}

We obtained totally 27 different statements on good master degree dissertation through analyzing with software Nvivo 10. The statements which its holders are more than $5 \%$ are shown in Table 2.

As Table 2 shown, the majority (71.62\%) of candidates thought the characteristic of good master dissertation was that its novel views were usually. More than a half (64.85\%) of candidates thought the characteristic of good master dissertation was that its view was valuable and its content was rich. More than one forth candidates 
Table 1. The cognition of dissertation.

\begin{tabular}{lcc}
\hline Statements & $\begin{array}{c}\text { Number of candidates } \\
\text { (The total is 74) }\end{array}$ & $\begin{array}{c}\text { Percentage } \\
\text { (The total is 74) }\end{array}$ \\
\hline A paper with rational structure & 58 & 78.37838 \\
A paper with rich content and enough number of words & 43 & 58.10811 \\
A paper with new title & 24 & 32.43243 \\
A paper with standard form & 21 & 28.37838 \\
A paper which of academic value & 16 & 21.62162 \\
A paper with clear views & 15 & 20.27027 \\
A paper with systematic content & 14 & 18.91892 \\
A paper submitting a scientific research & 11 & 14.86486 \\
A paper which has a analysis of a problem & 7 & 9.459459 \\
A paper which includes reasonable method & 5 & 6.756757
\end{tabular}

Table 2. The cognition of good dissertation.

\begin{tabular}{|c|c|c|}
\hline Statements & $\begin{array}{l}\text { Number of candidates } \\
\text { (The total is 74) }\end{array}$ & $\begin{array}{c}\text { Percentage } \\
\text { (The total is 74) }\end{array}$ \\
\hline A paper with novel views & 53 & 71.62162 \\
\hline A paper with greater academic value & 48 & 64.86486 \\
\hline A paper with richer content & 46 & 62.16216 \\
\hline A paper with good arrangement of chapters & 19 & 25.67568 \\
\hline A paper which includes reasonable method & 16 & 21.62162 \\
\hline A paper with rich theory & 11 & 14.86486 \\
\hline A paper which has many research methods & 10 & 13.51351 \\
\hline A paper with standard form & 9 & 12.16216 \\
\hline A paper which has novel title & 7 & 9.459459 \\
\hline A paper which can be published on academic journals & 4 & 5.405405 \\
\hline
\end{tabular}

thought the characteristic of good master dissertation was its quite reasonable arrangement of chapters was.

\subsection{The Cognition of Preparing for Master Degree Dissertation}

We obtained totally 18 different statements on preparing for master degree dissertation after analyzing with software Nvivo 10. The statements which its holders are more than 5\% are shown in Table 3.

As Table 3 shown, almost all (98.65\%) candidates thought reading more relevant literature to understand research status was necessary before writing dissertation. The majority $(75.68 \%)$ of candidates thought they should learn more fundamental theories. Only 16.22\% candidates thought they should learn more research methods.

\subsection{The Cognition on How to Write a Master Degree Dissertation and the Principles}

Related to how to write a master degree dissertation and what principles should follow, we totally obtained 28 different statements. The statements which its holders are more than 5\% are shown in Table 4.

From Table 4, we know the majority (72.97\%) of candidates thought they should refer the form of relevant dissertation usually when writing dissertation. About one third candidates thought they should investigate in 
Table 3. Statements on preparing for dissertation.

\begin{tabular}{lcc}
\hline Statements & $\begin{array}{c}\text { Number of candidates } \\
\text { (The total is 74) }\end{array}$ & $\begin{array}{c}\text { Percentage } \\
\text { (The total is 74) }\end{array}$ \\
\hline Reading more literature to understand research status & 73 & 98.64865 \\
Mastering more fundamental theories & 56 & 75.67568 \\
Preparing title earlier & 19 & 25.67568 \\
Learning the form of dissertation & 16 & 21.62162 \\
Learning more research methods & 12 & 16.21622 \\
Discussing with supervisors and classmates & 8 & 10.81081 \\
Improving the ability of words expression & 5 & 6.756757 \\
\hline
\end{tabular}

Table 4. The cognition on writing dissertation.

\begin{tabular}{lcc}
\hline Statements & $\begin{array}{c}\text { Number of candidates } \\
\text { (The total is 74) }\end{array}$ & $\begin{array}{c}\text { Percentage } \\
\text { (The total is 74) }\end{array}$ \\
\hline Referring the form of relevant dissertation usually & 54 & 72.97297 \\
Investigating in-depth & 28 & 37.83784 \\
Determining a appropriate title & 23 & 31.08108 \\
Asking teachers usually & 19 & 25.67568 \\
Combining practice closely & 19 & 25.67568 \\
Revising patiently & 9 & 12.16216 \\
Discussing with classmates usually & 8 & 10.81081 \\
Having a whole writing program & 7 & 9.459459
\end{tabular}

depth, about one fourth candidates thought they should ask supervisors and combine the mathematics teaching practices. Only about one tenth candidates thought they should make a detailed writing program when they started their dissertation.

\section{Discussion}

Based on the results above, majority of candidates pay more attention to the external form of master degree dissertation, such as the richness of content, standardization of form, rationality of arrangement of chapters and the novelty of title. They thought the above were the essential factors of a master degree dissertation. They seldom mention the research work which is related to the dissertation, especially the relevant demonstration of argument and the research methods. So the present candidates' overall cognition on master degree dissertation is relatively superficial, some of them even are inaccurate and false. The master degree dissertation definitely needs standardization of form, rationality of arrangement of chapters and the novelty of title [5], however, they are absolutely not essential. Besides most candidates' cognition on master degree dissertation has obvious loopholes, they do not recognize the essential factors of appraising dissertation's quality are the researches submitted in the dissertation and the author's demonstration of argument yet.

Most candidates thought that reading more relevant literature to understand research status, learning more fundamental theories and having a good title were necessary when they prepared for their dissertation. Almost no one recognized that a deep research was considerably important for preparing for their dissertation. We cannot claim the candidates' cognition on preparing for their dissertations are false completely, however, they obviously did not recognize the relationship of research work and dissertation and not understand the general procedure of preparing for a dissertation yet. Since if they had recognized that, they must pay special attention on research works and do some research work when they prepared for their dissertation and before writing. 
Concerning the factors which should be paid attention to in process of writing dissertation, most candidates still emphasize the standardization of form, so undoubtedly the external shape is their first priority. Almost no one recognized it was necessary to present research method, process and result unambiguously and completely and in order when they wrote dissertation. Almost no one recognized that the explicit and objective views and its full demonstration were the most important. No one mentioned deep thinking and revising carefully. So the candidates' cognition about writing dissertation needs to be corrected and adjusted comprehensively.

\section{Conclusions}

Even though the participants recruited and the questions asked in the process of investigating are not so many, the results we obtained are unquestionably significant. Based on the results above, we know many candidates' cognition about dissertation and its preparing and writing is quite superficial, some of them are even false, since they merely recognize the richness of content, standardization of structure, mastering more fundamental theories and reading more relevant literature, etc., but do not fully recognize the importance of research work to dissertation and the relationship between them.

Hence it is necessary to introduce the knowledge completely about master dissertation to full time master of mathematics education candidates. When the knowledge is introduced, the importance of research work to dissertation and the relationship between them must be an emphasis. Present candidates should know that accumulating fundamental theories and reading relevant literature are important for writing dissertation, but the most important is the research work. Present candidates should also know that the standardization of form and having a novel title are necessary to dissertation, but the explicit views and their fully demonstration are more important. The candidates should be told to think in depth and revise usually and carefully and have an integral detailed writing program when they write the dissertation.

\section{Funding}

Supported by the project of research on enhancing quality of full-time master of mathematics education candidate's dissertation (SDYC14048).

\section{References}

[1] Hou, Zh.T. (2010) Research on Quality Assurance of Master of Education Dissertation: Reviews and Reflection. Academic Degrees \& Graduate Education, 6, 40-44.

[2] Yang, Q.L. (2005) The Problems and Its Explanation Appeared in Practice of Master Education. Research in Educational Development, 6, 77-80.

[3] Li, G.F. and Yang, Z.P. (2011) The Problems, Reasons and Countermeasures of Master of Education Dissertations. Academic Degrees \& Graduate Education, 2, 20-25.

[4] Zhang, D.Q. (2011) Mathematics Education for the Master Degree Thesis Writing Analysis of the Investigation. Journal of Mathematics Education, 6, 25-29.

[5] Wang, X.W. (2010) The Guidance to National Excellent Dissertation of Master of Education. Academic Degrees \& Graduate Education, 10, 35-39. 